\title{
Editorial: E-learning and Knowledge Management in the Early Years: Where Are We and Where Should We Go
}

\author{
Hui Li*
}

Faculty of Education, The University of Hong Kong, Pokfulam Road, Hong Kong

E-mail: huili@hkucc.hku.hk

*Corresponding author

\section{Jennifer Masters}

Faculty of Education, La Trobe University, Bendigo Campus, PO Box 199, Victoria 3552, Australia

E-mail: j.masters@latrobe.edu.au

\begin{abstract}
E-learning and knowledge management are increasingly accepted as established practices in the field of early childhood education. Living in the age of Web 2.0, young children can learn through experience, application, and conversation in community, physically or virtually, with peers, parents, teachers, and other adults, beyond the classroom and across the media. These concepts are of growing interest in communities of practice and knowledge networks. Although most early childhood educators recognize and practice some kinds of e-learning, most have yet to master the basic theory and practice of knowledge management. What does e-learning mean for young children? How do we apply knowledge management in early childhood setting? These questions are of great importance and a special collection such as this issue will be beneficial to take stock of the ongoing practices as well as to explore future directions in the field. This issue will combine knowledge management and elearning with early childhood education to provide a valuable arena for the discussion and dissemination of this topic and related studies.
\end{abstract}

Keywords: Early Childhood, E-learning, Knowledge Management

Biographical notes: Hui $\mathrm{Li}$ is an assistant professor of early childhood development and education in the Division of Learning, Development and Diversity, Faculty of Education, The University of Hong Kong. His research interests lie in early child development, Chinese literacy development and education, early childhood language acquisition (Cantonese and Mandarin), early childhood curriculum and pedagogy, school-based development and educational policy. He is the author and coauthor of over one hundred articles and publications. For more information about Dr. Li, please refer to his official homepage: http://web.edu.hku.hk/academic_staff.php?staffId=huili

Jennifer Masters is a senior lecturer in Information and Communication Technology (ICT) in Education and the Bachelor of Education Course Coordinator at Latrobe University, Bendigo. She has taught in schools at both Early Childhood and Primary levels and specializes in the integration of ICT in curriculum. Her research interest areas include informal learning, social networking, using ICT for "real" purposes, publishing and presenting with computers, and computer-based problem-solving opportunities. She completed her $\mathrm{Ph}$. D thesis relating to young children using computers, with a focus on 
how teachers can "scaffold" or support children working with computers. Her thesis was published as a book in 2008 - Teachers scaffolding children working with computers: An analysis of strategies. Jennifer's current research relates to the use of computers and associated technologies in informal contexts. She is particularly interested in children engaging in social networking, cybercitizenship and the use technology for creative purposes, such as digital storytelling and animation.

\section{Introduction}

E-learning and knowledge management are increasingly accepted as established practices in the field of early childhood education. Living in the age of Web 2.0, young children can learn through experience, application, and conversation in community, physically or virtually, with peers, parents, teachers, and other adults, beyond the classroom and across the media. These concepts are of growing interest in communities of practice and knowledge networks. Although most early childhood educators recognize and practice some kinds of e-learning, most have yet to master the basic theory and practice of knowledge management. What does e-learning mean for young children? How do we apply knowledge management in early childhood setting? These questions are of great importance and a special collection such as this issue will be beneficial to take stock of the ongoing practices as well as to explore future directions in the field. This issue will combine knowledge management and e-learning with early childhood education to provide a valuable arena for the discussion and dissemination of this topic and related studies.

\section{E-learning: What, Why, and How}

E-learning is the learning that takes place in an electronically simulated environment (Anonymous, 2009). While the "e" is generally accepted as representing "electronic", the connotations of "e" are perhaps more far reaching. In our perspective, "e" does represent "electronic" but it could also represent, evolving, enhanced, extended, everywhere, everytime, and everybody. E-learning can be done anywhere and anytime as long as the learner has the access. It uses a variety of media like audio, text, virtual environments, video, and animation, both offline and online. Further, effective e-learning thrives at the nexus of web usability, communication, relationship, document, and knowledge management tools, and can dramatically enhance a learner's learning experience (Srimathi \& Srivatsa, 2008).

E-learning has the potential to immerse students completely within an environment conducive to learning. This offers an alternative to classroom-style learning. First, elearning allows the learner learn about the subject at his or her own pace, without the risk of missing valuable information. This also means the learner can decide on his or her own to study a particular topic more closely as well as to skip over the topics that he or she already knows. Learners can easily review topics whenever the need arises. Second, elearning puts the learner in an interactive environment where objects in the learning environment can be readily adjusted, modified or manipulated according to the user's preference. This can enhance the learning process. Interactivity can be as simple as clicking on the appropriate answer to a question posed at the end of a session or it can be as complex as manipulating multiple objects to explore concepts or to perfect a skill. Third, e-learning can be accessed via the web at any time and in many locations. Students 
can choose when and how much time to devote to the learning of a chosen topic. Learners can fit their learning activities easily with their daily routine. They need not leave home to participate in an e-learning program and learning does not require complex logistics. All a participant needs is a computer, Internet connectivity, and access to the web. Finally, e-learning materials are flexible and can be adjusted, revised and redesigned to suit the learner needs. Activities can be easily added and incorporated. Nowadays the e-learning software can also be automatically updated by connecting to the server (Ivanescu, Barda, \& Vladicescu, 2008).

There are many forms of e-learning, which could be classified into the following four major types. First, online learning is a form of Internet-based or network-based elearning that is widely used today. Google and Yahoo, for example, can be regarded as the two of the largest online databases, where learners can browse through different topics to look for an answer or an explanation to various questions. Second, online support is a more interactive form of e-learning as it gives the learner an opportunity to interact with professionals who can provide an explanation or answer to a problem. These online support systems could be in the form of chat rooms, forums, emails, bulletin boards, instant messaging applications, and others that can better help the learner resolve their problems by providing more specific or tailored answers. Third, offline e-learning programs could help learners learn through stored modules. This type of e-learning could also be self-paced and interactive. Last, some programs even use a real-time method of elearning with live interaction between the instructors and the learners. This kind of elearning is nearest to classroom-style learning as learners can raise their electronic hands, view a common blackboard and interact with each other.

E-learning 2.0, as coined by Downes (2005), is widely used to refer to e-learning that is more interactive and socialized. Teachers and students are embracing web technologies such as blogging and podcasting, which are not designed specifically for use in education but are really helping to make e-learning far more personal, social, and flexible (Mushtaha \& Troyer, 2007). Originally, "e-learning" (e-learning 1.0) referred to the use of a Virtual Learning Environment (VLE), software that was cumbersome and expensive and tended to be structured around courses, timetables, and testing. This was often driven by the needs of the institution rather than the individual learner. In contrast, e-learning 2.0 takes a small pieces, loosely joined approach that combines the use of discrete but complementary tools and web services — such as blogs, wikis, and other social software - to support the creation of ad-hoc learning communities (Downes, 2005).

The term e-learning 2.0 is used to refer to new ways of thinking about e-learning inspired by the emergence of Web 2.0. From an e-learning 2.0 perspective, conventional e-learning systems were based on instructional packets that were delivered to students using Internet technologies. E-learning 2.0, by contrast to e-learning 1.0, is built around collaboration, and places increased emphasis on social learning and use of social software such as blogs, wikis, podcasts and virtual worlds (Mushtaha \& Troyer, 2007). E-learning 2.0 reconceptualizes knowledge as meaning and understanding that is socially constructed. Learning in the early years takes place through conversations about content and grounded interaction about problems and actions. Advocates of social learning claim that one of the best ways to learn something is to teach it to others, which is exactly the essential element of e-learning 2.0. Although the genre of e-learning is very suited to early years interactions, the use of e-learning with young children is embryonic and yet to become a significant component of early childhood education. 


\section{Knowledge Management: Reconceptualization of Early Childhood Curriculum}

Knowledge management $(\mathrm{KM})$ is the collection of processes that govern the creation, dissemination, and utilization of knowledge (Logan, 2000). It is the organizational activity of creating the social environment and technical infrastructure so that knowledge can be accessed, shared and created (Logan, 1997, p. 23). In a traditional sense, knowledge management has been practiced in varying forms for a very long time, by people such as philosophers, priests, teachers, politicians, scribes, and librarians. Perhaps it is time for us to also reconceptualize early childhood curriculum with this brand new perspective and framework.

There are various perspectives as well as frameworks on knowledge management. For example, it can be defined as the ability to manage "knowledge", which is per se a kind of information. Or, KM could be regarded as an audit of "intellectual assets" that highlights unique sources, critical functions and potential bottlenecks which hinder knowledge flows to the point of use. Business management scientists define KM as the systematic process of finding, selecting, organizing, distilling and presenting information in a way that improves an employee's comprehension in a specific area of interest. Computer scientists tend to define KM as organizing knowledge repositories (data bases) so as to allow for easy retrieval and exchange of the information stored therein. Important concepts in knowledge management include domains (fields of related concepts and terms) and ontologies (structures of interrelated terms for things, concepts, and relationships in a given domain). Early childhood curriculum could also be viewed as a know management system that include domains and ontologies to be learnt by young children.

Further, knowledge management embraces the perspective that knowledge is dynamically imbedded in networks and processes as well as in the human beings that constitute and use them. This is very similar to the postmodernism perspective of early childhood curriculum. Under the postmodernism view, knowledge is socially constructed and contextually dependent (Kilgore, 2001). Postmodernism welcomes uncertainties, complexities, subjectivities, and diversities, because there are multiple realities, multiple perspectives, and multiple learners in the world. It is reasonable that KM could be used to reconceptualize early childhood curriculum as a collection of processes that govern the creation, dissemination, and utilization of knowledge for varying young children in the postmodern era.

\section{Introduction of This Special Issue}

The immersion of young children in the Web 2.0 as a result of progress might have struck casual observers as trivial, possibly alarming, or conceivably advantageous. Careful investigation is called for, and who better to pursue it than early childhood researchers? Curiously, early childhood educators have been relatively disinclined to address young children's interests in "playing" with information and communication technology (ICT). That is, we tend to overlook a large part of what young children do in their daily life. The goals of this Special Issue are to bring together a variety of perspectives on the ways in which young children and their teachers use, live with, react to, learn from, and learn about the omnipresent e-communications tools of contemporary life.

In the first paper of this special issue, Sandra Hesterman presents a case study of the Willy Wagtail Tale to show us how knowledge management and e-learning can enrich 
multiliteracies in the early years. It is a pity that using ICT to support multiliteracies learning in the early years remains a seriously under-researched area. This paper showcases how knowledge management and e-learning is socially constructed to enrich multiliteracies experiences in a small Western Australian school.

In the second paper, $\mathrm{Li}$ and Rao surveyed 55 Chinese kindergarten teachers from Shenzhen and Hong Kong to understand their beliefs and reported practices about multiple literacies related to e-learning in the early years. They found that early childhood practitioners in Chinese societies started to promote early child multiliteracies using ICTs, but the critical barrier is whether there are enough resources for e-learning provided in the classroom.

The third paper, by Zhou and her team, investigated the current needs and future development of using e-resources for early childhood curriculum in China. This paper analyzed the major digital resources in China and found that the e-resource should have features of individualization, interaction, sharing and sociability in networking in Chinese educational contexts to support teaching design, practice, evaluation and reflection. They suggest an effective framework of e-resources: teacher planning system to support teachers' knowledge exchange, children's learning system to provide e-learning at school or home, and family support system to involve parents in their children's learning and development.

Masters and Barr, in the last paper, report a case study of SuperClubsPLUS, which is an online learning community for children 6-12 to participate in social networking. This study has investigated what Australian children do in SuperClubsPLUS, how they interact with peers and what skills they have learnt. It has also examined their cyber safety skills in the context of transferability, because the children of this age are potentially just as vulnerable to cyber safety issues as their older peers.

E-learning and knowledge management in the early years is an emerging research field of theoretical significance and practical importance. There are wide ranging implications for government policy and the balance of competing interests. ICT is among human beings' most distinctive, most revolutionary, and most far-reaching tools. Through ICT, we have transformed human existence and learning, dramatically and rapidly. In a period of proliferating and diversifying new ICT, these processes are accelerating. Nowadays, e-learning is omnipresent in the lives of young children, but we have been too ready to take young children's adaptations to these tools for granted. We hope that we have been able to persuade some readers that we should not and we are confident that the contributors to this Special Issue will demonstrate that the study of young children and e-learning and knowledge management will be enormously rewarding.

\section{Acknowledgements}

We are greatly indebted to Dr. Maggie M. Wang for her encouragement of the idea of this Special Issue and for her spiritual support throughout. We are also very grateful to Miss Jessie Wong who acted as a reviewer and editor of the submitted manuscripts. Thanks also go to those anonymous reviewers in Hong Kong and Australia. Their efforts have contributed enormously to the finished collection. 


\section{References}

1 Anonymous (2009). What is e-learning. Retrieved November 30, 2009, from http://www.tech-faq.com/E-learning.shtml.

2 Downes, S. (2005, October 17). E-learning 2.0. National Research Council of Canada. Retrieved November 30, 2009, from http://www.elearnmag.org/subpage.cfm?article=29-1\&section=articles.

3 Ivanescu, A., Barda, I, \& Vladicescu, F. P. (2008). Distance learning answering students' needs: The example of the interactive e-learning environment (IELE). The Proceedings of the Fourth International Scientific Conference on E-learning and Software for Education, Bucharest.

4 Kilgore, D.W. (2001). Critical and postmodern perspectives on adult learning. New Directions for Adult and Continuing Education, 2001(89), 53-62.

5 Logan, R.K. (2000). The sixth language: Learning a living in the Internet age. Physics.utoronto.ca. Retrieved November 30, 2009, from http://physics.utoronto.ca.

6 Logan, R.K. (1997). The fifth language: Learning and living in the computer age. Toronto: Stoddard Pub.

7 Mushtaha, A., \&, Troyer, O. D. (2007). Cross-cultural understanding of content and interface in the context of e-learning systems. Lecture Notes in Computer Science (Volume 4559), 164-173. Springer Berlin / Heidelberg.

8 Srimathi, H., \& Srivatsa, S. K. (2008). Knowledge representation in personalized elearning. Academic Open Internet Journal, 23. Retrieved November 30, 2009, from http://www.acadjournal.com/2008/v23/part6/p4/ 